Research Article

\title{
Study on Buckling Behavior of Tapered Friction Piles in Soft Soils with Linear Shaft Friction
}

\author{
Junxiu Liu, ${ }^{1,2}$ Xianfeng Shao, ${ }^{3}$ Baoquan Cheng $\mathbb{D}^{4},{ }^{4}$ Guangyong Cao $\mathbb{D}^{1,2}$ and Kai Li $\mathbb{D}^{1,2}$ \\ ${ }^{1}$ College of Civil Engineering, Anhui Jianzhu University, Hefei, Anhui 230601, China \\ ${ }^{2}$ Anhui Province Key Laboratory of Building Structure and Underground Engineering, Anhui Jianzhu University, Hefei, \\ Anhui 230601, China \\ ${ }^{3}$ State Grid Anhui Electric Power Co., Ltd. Construction Company, Hefei, Anhui 230001, China \\ ${ }^{4}$ Department of Civil and Environmental Engineering, The Hong Kong Polytechnic University, Kowloon, Hong Kong, China
}

Correspondence should be addressed to Kai Li; kli@ahjzu.edu.cn

Received 27 May 2020; Revised 23 June 2020; Accepted 4 July 2020; Published 24 July 2020

Academic Editor: Xue Zhang

Copyright (c) 2020 Junxiu Liu et al. This is an open access article distributed under the Creative Commons Attribution License, which permits unrestricted use, distribution, and reproduction in any medium, provided the original work is properly cited.

\begin{abstract}
The buckling instability of long slender piles in soft soils is a key consideration in geoengineering design. By considering both the linear shaft friction and linear lateral stiffness of the soft soil, the buckling behaviors of a tapered friction pile embedded in heterogeneous soil are extensively studied. This study establishes and validates an analytical model to formulate the equilibrium equations and boundary conditions and then numerically solves the boundary value problem to obtain the critical buckling load and buckling shape by using software Matlab. The effects of boundary conditions, tapered ratio, stiffness ratio, friction ratio, lateral stiffness, and shaft friction on the buckling behavior of the friction pile are extensively explored. This study demonstrates that the buckling load decreases with the increase of friction ratio of the linear shaft friction. There exists an optimal tapered ratio corresponding to the maximum dimensionless buckling load in the tapered friction pile with linear shaft friction. The result means that the linear shaft friction should be considered in designing the tapered friction piles in heterogeneous soils. The results also have potential applications in the fields of growing of tree roots in soils, moving of slender rods in viscous fluids, penetrating of fine rods in soft elastomers, etc.
\end{abstract}

\section{Introduction}

Tapered friction piles have the advantages of small settlement, fast construction speed, and high economic benefits and have been widely used in road and bridge engineering at present. Piles are often subjected to large axial compressive loads from the road and bridge and can buckle, even when embedded inside an soft elastomeric matrix [1-4]. In recent years, buckling behaviors have drawn considerable attention in microtubules [5], fiber-reinforced composites [6], pipelines on seabeds [7], plant roots growing in soil [8], packaged DNA in viruses [9], silicon nanowire attached to a soil substrate [10], and coil tubing in oil-field operations [11]. Because slender piles are prone to buckling and instability, it is a key problem in geotechnical engineering design. Especially when the foundation soil is very soft and the pile is slender, the compressed pile is prone to destabilization under the action of axial force, and it is necessary to analyze the destabilization [12]. In addition, in the engineering design of piles, it is generally assumed that the buckling instability of piles is not considered when they are fully embedded, but this general design principles are no longer valid when the cross-section of piles has a high bearing capacity or stress.

In the field of buckling behaviors of piles, a lot of research work has been carried out in-depth [13-21]. Modeling the interaction between embedded piles and soils is very crucial in the analysis of pile stability and dynamic behaviors [22, 23]. The classical method is to assume that the effect of elastic foundation on the pile embedded in it is simplified to a series of springs along the pile length [24]. Winkler foundation model by Hetenyi has been widely used in buckling analysis of 
pile subjected to lateral loads from the soil foundation [24]. Based on the Winkler foundation model, Davison et al. explored the stability in the pile-soil system under various constraints $[25,26]$. Reddy and Valsangkar used the energy method to analyze the buckling of piles and obtained the bearing capacity of piles [27]. An elastic Winkler foundation with spring stiffness varying linearly with depth was established to explore the stability of a pile and the bearing capacity of the pile and buckling modes were presented [28]. Chen et al. used the cusp catastrophe theory, investigated the stability of a pile under various boundary conditions, and obtained the critical load for the pile buckling [29]. A buckling analysis method for fully embedded single pile in elastic foundation under axial load based on modified Vlasov foundation model is proposed, and the numerical results illustrate that the medium stiffness has significant influence on the buckling behaviors [30]. In order to study the stability of the pile partially embedded in elastic foundation, the soil modulus was assumed to have power distribution along the length of piles [31]. In order to study buckling behaviors of piles in liquefied foundation for the seismic design, a nonlinear Winkler foundation model was established and solved numerically [32].

In the previous studies, the transfer of the axial load along the direction of the pile is not considered, and it is considered that the compressive load is unchanged throughout the body of pile. However, this assumption is only applicable to short end-bearing pile. In fact, the tangential resistance has some influence on the buckling of friction piles. So far, little work has considered the axial friction in pile-soil system. The effect of the friction force on the buckling load of the embedded pile was analyzed based on the Winkler foundation model [33]. Buckling analysis of piles with constant shaft friction has also been investigated in detail by other different methods [34]. Recently, buckling behaviors of tapered piles attracts much attention [35-37]. Lee studied and analyzed the buckling behavior of endbearing piles and gave the influence of tapered ratio and section shape on the buckling behavior of piles [36]. Lee also explored the behaviors of buckling of tapered piles with constant shaft friction in heterogeneous soils by assuming linear lateral stiffness and found that there exists an optimal tapered ratio for a maximum buckling load factor [37].

Previous studies have assumed that the shaft friction resistance is constant, which is obviously not suitable for piles in heterogeneous soils. In current research studies, the statistical theory and random field are usually considered to describe the complex heterogeneous property of soil [38]. To simplify the theoretical formulation, both linear lateral stiffness and linear lateral friction resistance are assumed, and the stability of a tapered friction pile in heterogeneous soils is studied by establishing a theoretical model in this paper. This study will focus on exploring the effect of the friction ratio of the linear friction on buckling behaviors in the tapered friction piles in heterogeneous soils. Firstly, the theoretical model is established, and the equilibrium equation and boundary conditions of the fully embedded tapered friction pile are derived. Then, the boundary value problem is solved numerically by using software Matlab. The results show that this method is very effective in analyzing the buckling behavior in the pile-soil system. In this paper, the influence of various geometric parameters and material properties, including boundary conditions, tapered ratio, stiffness ratio, friction ratio, lateral stiffness, and shaft friction, on the buckling behavior of fully embedded tapered friction piles is fully discussed.

\section{Theoretical Model and Formulation}

Figure 1(a) schematics the fully embedded vertical tapered pile with length $L$ and square cross-section in an inhomogeneous soil. The pile is assumed to be homogeneous and elastic, and the side length of the cross-section in the pile varies longitudinally.

A linear function for the geometry of the pile is considered as

$$
T(x)=\left[1+(m-1) \frac{x}{L}\right],
$$

in which the tapered ratio $m$ is defined as the ratio of the bottom side length $w_{b}$ to the top side length $w_{t}$ of the pile. Through simple geometric analysis, the side length at any position of the pile can be described as

$$
w(x)=\frac{2 w_{e}}{m_{1}}\left(1+m_{2} \frac{x}{L}\right),
$$

where $w_{e}$ is the side length at the middle of the pile, $m_{1}=m+1$, and $m_{2}=m-1$.

Similarly, the perimeter $u$ and moment of inertia $I$ at any position of the pile are, respectively, expressed as

$$
\begin{aligned}
& u(x)=\frac{2 u_{e}}{m_{1}}\left(1+\frac{m_{2}}{L} x\right), \\
& I(x)=\frac{16 I_{e}}{m_{1}^{4}}\left(1+\frac{m_{2}}{L} x\right)^{4},
\end{aligned}
$$

where $u_{e}=4 w_{e}$ and $I_{e}=\left(w_{e}^{4} / 12\right)$ are the perimeter and moment of inertia of the cross-section at the middle of the pile, respectively.

For fully buried piles, the lateral stiffness of the soil can be expressed by elastic Winkler foundation. In this paper, it is assumed that the horizontal coefficient of subgrade reaction of the soil increases linearly with depth. A linear function for the lateral stiffness of the soil is considered as

$$
H(x)=\left[1+(n-1) \frac{x}{L}\right],
$$

in which the stiffness ratio $n=\left(k_{b} / k_{t}\right)$ in the formula is defined as the ratio of the horizontal coefficient of subgrade reaction $k_{\mathrm{b}}$ at the bottom to the horizontal coefficient of subgrade reaction $k_{\mathrm{t}}$ at the top of the pile.

The horizontal coefficient of subgrade reaction of the soil at any depth is estimated as

$$
k(x)=\frac{2 k_{e}}{n_{1}}\left(1+\frac{n_{2}}{L} x\right),
$$


where $k_{e}$ is the horizontal coefficient of subgrade reaction of the soil at midpoint of the pile length, $n_{1}=n+1$, and $n_{2}=n-1$.

The tangential interaction between pile and surrounding soil is described by unit shaft friction, which is defined as the tangential frictional force acting on the side surface of the pile per length. A linear function for the unit shaft friction is also defined as

$$
G(x)=\left[1+(s-1) \frac{x}{L}\right]
$$

where $s=\left(f_{b} / f_{t}\right)$ is the friction ratio, in which $f_{b}$ and $f_{t}$ are the unit shaft frictions at the bottom and top of the pile, respectively.

The coefficient of unit shaft friction at any depth can be easily estimated as

$$
f(x)=\frac{2 f_{e}}{s_{1}}\left(1+\frac{s_{2}}{L} x\right)
$$

where $f_{e}$ is the coefficient of unit shaft friction at midpoint of the pile length, $s_{1}=s+1$, and $s_{2}=s-1$.

As shown in Figure 1(b) of the free-body diagram of the pile, the ordinary differential equations for equilibrium of the element can be obtained:

$$
\left\{\begin{array}{l}
\frac{\mathrm{d} N}{\mathrm{~d} x}+f u=0, \\
\frac{\mathrm{d} V}{\mathrm{~d} x}+k w y=0 \\
\frac{\mathrm{d} M}{\mathrm{~d} x}-V+N \frac{\mathrm{d} y}{\mathrm{~d} x}=0
\end{array}\right.
$$

in which $N$ is the axial force, $V$ is the shear force, and $M$ is bending moment on the cross-section of the pile. The bending moment can be expressed by deflection of the pile as

$$
M=E I \frac{\mathrm{d}^{2} y}{\mathrm{~d} x^{2}}
$$

in which $E$ is Young's modulus of the pile which is assumed to be constant. By substituting equation (9) into equation (8), the equilibrium governing equation of the pile can be obtained as

$$
E I \frac{\mathrm{d}^{4} y}{\mathrm{~d} x^{4}}+2 E \frac{\mathrm{d} I}{\mathrm{~d} x} \frac{\mathrm{d}^{3} y}{\mathrm{~d} x^{3}}+\left(E \frac{\mathrm{d}^{2} I}{\mathrm{~d} x^{2}}+N\right) \frac{\mathrm{d}^{2} y}{\mathrm{~d} x^{2}}-f u \frac{\mathrm{d} y}{\mathrm{~d} x}+k w y=0 .
$$

According to equation (8), the axial force of the pile can be calculated as

$$
N=P-\int_{0}^{x} f u \mathrm{~d} x
$$

Inserting the shaft friction in equation (7) and perimeter in equation (3) into equation (11) leads to

$$
N=P-\frac{4 f_{e} u_{e}}{s_{1} m_{1}}\left(x+\frac{s_{2}+m_{2}}{2 L} x^{2}+\frac{s_{2} m_{2}}{3 L^{2}} x^{3}\right) .
$$

To facilitate discussion, the following dimensionless variables and parameters are introduced:

$$
\begin{aligned}
& \bar{x}=\frac{x}{L}, \\
& \bar{y}=\frac{y}{L}, \\
& \kappa=\frac{w_{e}}{L}, \\
& \alpha=\frac{L}{\lambda}, \\
& \beta=\frac{u_{e} f_{e} \lambda^{3}}{\pi E I_{e}}, \\
& b=\frac{B L^{2}}{\pi^{2} E I_{e}},
\end{aligned}
$$

where $\bar{x}$ represents the dimensionless vertical position of the pile, $\bar{y}$ represents the dimensionless horizontal position of the pile, $\kappa$ represents dimensionless side length of the pile, $\alpha$ represents the dimensionless characteristic length, $b$ represents the dimensionless buckling load of the pile, $\beta$ represents the dimensionless friction resistance of the soil, and $\lambda$ represents the dimensionless stiffness between the pile and the soil, defined as $\lambda=\sqrt[5]{E I_{e} / k_{e}}$.

Then, the equilibrium equation (10) can be rewritten as

$$
\begin{aligned}
& {\left[\frac{12 m_{2}^{2}}{\left(1+m_{2} \bar{x}\right)^{2}}+\frac{\pi^{2} m_{1}^{4} b}{16\left(1+m_{2} \bar{x}\right)^{4}}-\frac{\pi m_{1}^{3} \alpha^{3} \beta}{4 s_{1}\left(1+m_{2} \bar{x}\right)^{4}}\right.} \\
& \left.\cdot\left(\bar{x}+\frac{s_{2}+m_{2}}{2} \bar{x}^{2}+\frac{m_{2} s_{2}}{3} \bar{x}^{3}\right)\right] \frac{\mathrm{d}^{2} \bar{y}}{\mathrm{~d} \bar{x}^{2}} \\
& +\frac{\mathrm{d}^{4} \bar{y}}{\mathrm{~d} \bar{x}^{4}}+\frac{8 m_{2}}{1+m_{2} \bar{x}} \frac{\mathrm{d}^{3} \bar{y}}{\mathrm{~d} \bar{x}^{3}}-\frac{\pi m_{1}^{3}\left(1+s_{2} \bar{x}\right) \alpha^{3} \beta}{4 s_{1}\left(1+m_{2} \bar{x}\right)^{3}} \frac{\mathrm{d} \bar{y}}{\mathrm{~d} \bar{x}} \\
& +\frac{m_{1}^{3}\left(1+n_{2} \bar{x}\right) \alpha^{5} \kappa}{4 n_{1}\left(1+m_{2} \bar{x}\right)^{3}} \bar{y}=0 .
\end{aligned}
$$

Combining with boundary conditions, buckling loads can be obtained by solving the equilibrium equations above. In practice, the constraint at the pile top is generally weak, and the moment and shear force are assumed to be zero. Therefore, the constraint at the pile top can be treated as free end. For the pile end, there are three typical cases in projects. When the soft soil is underlain by rock and the piles have large rock-socketed depth, the displacement and rotation angle at the pile end are generally constrained. In this condition, the constrain at the pile end is often treated as fixed end. For piles with small rock-socketed depth, only the displacement is generally constrained, and the constrain at the pile end should be treated as the hinged end. For the pile end embedded in the soft soil, the constraints of the pile end are generally weak and could be treated as free ends. In this paper, the three kinds of boundary conditions mentioned above are considered: free end, pinned end, and fixed end. At 


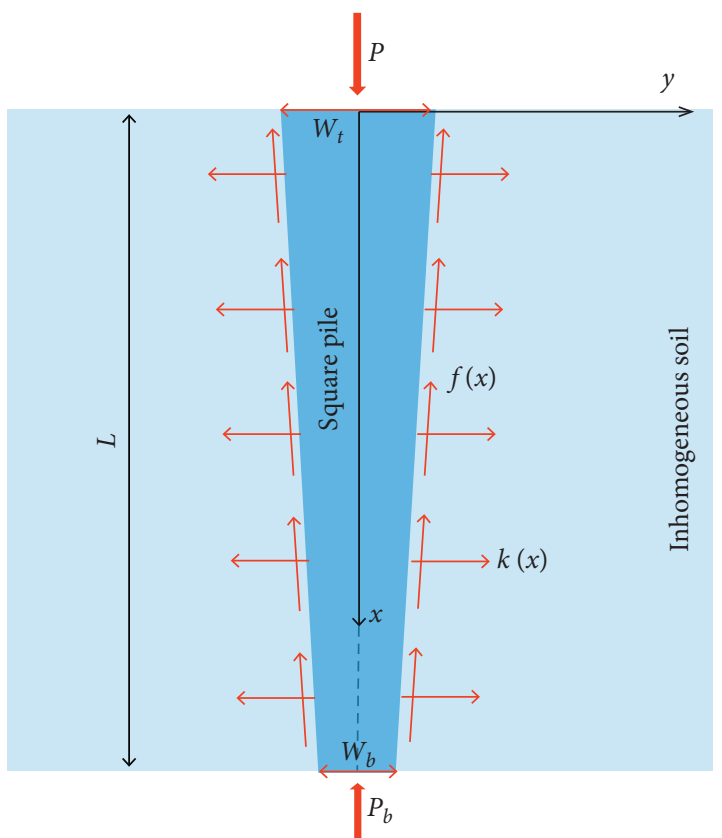

(a)

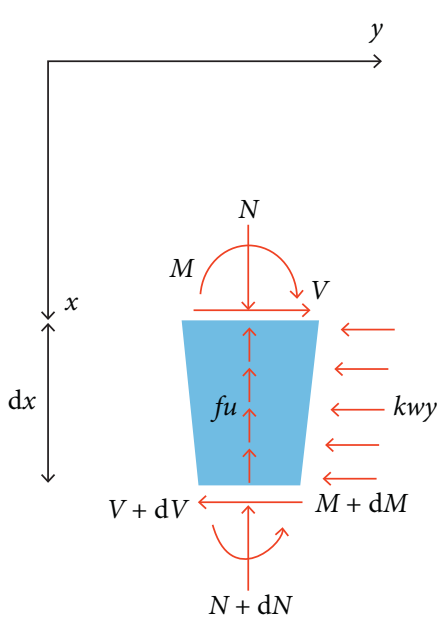

(b)

FIGURE 1: Schematics: (a) tapered friction piles in inhomogeneous soils with linear shaft friction and linear lateral stiffness; (b) free-body element.

the free end of the pile, both bending moment and shear force are zero. At the top of the pile, the boundary condition is described as

$$
\begin{gathered}
\frac{\mathrm{d}^{2} \bar{y}}{\mathrm{~d} \bar{x}^{2}}=0, \\
\frac{\mathrm{d}^{3} \bar{y}}{\mathrm{~d} \bar{x}^{3}}+\frac{\pi^{2} m_{1}^{4} b}{16} \frac{\mathrm{d} \bar{y}}{\mathrm{~d} \bar{x}}=0, \quad \text { at } \quad \bar{x}=0 .
\end{gathered}
$$

At the bottom of the pile, the boundary condition is derived as

$$
\begin{aligned}
& \frac{\mathrm{d}^{2} \bar{y}}{\mathrm{~d} \bar{x}^{2}}=0, \\
& \frac{\mathrm{d}^{3} \bar{y}}{\mathrm{~d} \bar{x}^{3}}+\left[\frac{\pi^{2} m_{1}^{4} b}{16\left(1+m_{2}\right)^{4}}-\frac{\pi m_{1}^{3} \alpha^{3} \beta}{4 s_{1}\left(1+m_{2}\right)^{4}}\right. \\
& \left.\quad \cdot\left(1+\frac{s_{2}+m_{2}}{2}+\frac{m_{2} s_{2}}{3}\right)\right] \frac{\mathrm{d} \bar{y}}{\mathrm{~d} \bar{x}}=0, \text { at } \bar{x}=1 .
\end{aligned}
$$

For the pinned end of the piles, the boundary condition is

$$
\begin{aligned}
\bar{y} & =0, \\
\frac{\mathrm{d}^{2} \bar{y}}{\mathrm{~d} \bar{x}^{2}} & =0 .
\end{aligned}
$$

For the fixed end of the piles, the boundary condition is

$$
\begin{aligned}
\bar{y} & =0, \\
\frac{\mathrm{d} \bar{y}}{\mathrm{~d} \bar{x}} & =0 .
\end{aligned}
$$

The critical axial stress of friction piles varies with different positions. The dimensionless buckling stress $\zeta_{b}$ can be defined as

$$
\zeta_{b}=\frac{\pi^{2} N}{A E}
$$

in which $A=\left(4 A_{e} T_{x}^{2} / m_{1}^{2}\right)$ and $A_{e}=w_{e}^{2}$. Using equation (8), buckling stress can be derived as

$$
\begin{aligned}
\zeta_{b}= & \frac{\pi^{4} m_{1}}{4 s_{r}^{2}\left(1+m_{2} \bar{x}\right)^{2}}\left[\pi m_{1} b-\frac{4}{s_{1}} \alpha^{3} \beta\left(\bar{x}+\frac{s_{2}+m_{2}}{2} \bar{x}^{2}\right.\right. \\
& \left.\left.+\frac{s_{2} m_{2}}{3} \bar{x}^{3}\right)\right],
\end{aligned}
$$

in which $s_{r}$ represents the slenderness ratio, defined as $s_{r}=\left(L / \sqrt{I_{e} / A_{e}}\right)$.

\section{Results}

3.1. Solution Method. The equilibrium equation (14) and the associated boundary conditions (15)-(18) present the boundary value problem for buckling of taped friction piles in inhomogeneous soils. To obtain the buckling load and buckling shape of the pile, the $b v p 4 c$ solver module in Matlab is used to solve the eigenvalue problem. To validate the mathematical formulation and numerical method, the taper ratio $m$ is set to be 1 to degenerate the solution in this study to the solution for the buckling of the uniform pile of Gabr [12]. Figure 2 shows the buckling load factors for three different end conditions obtained by using the model of Gabr et al. and this study, for $m=1, n=1, s=1, w_{e}=1 \mathrm{~m}$, $E=28.5 \mathrm{GPa}, k_{e}=7 \mathrm{MN} / \mathrm{m}^{3}$, and $f_{e}=35 \mathrm{kPa}$. The results 


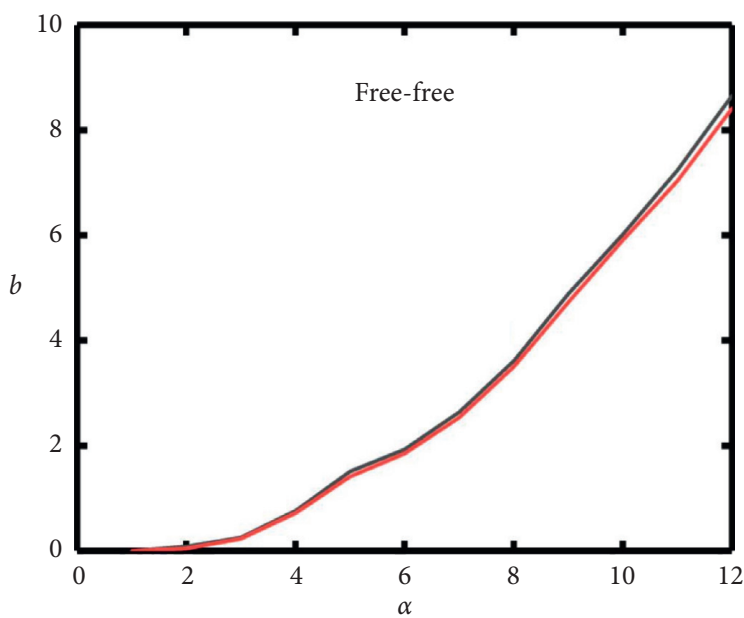

- Gabr et al. (1994)

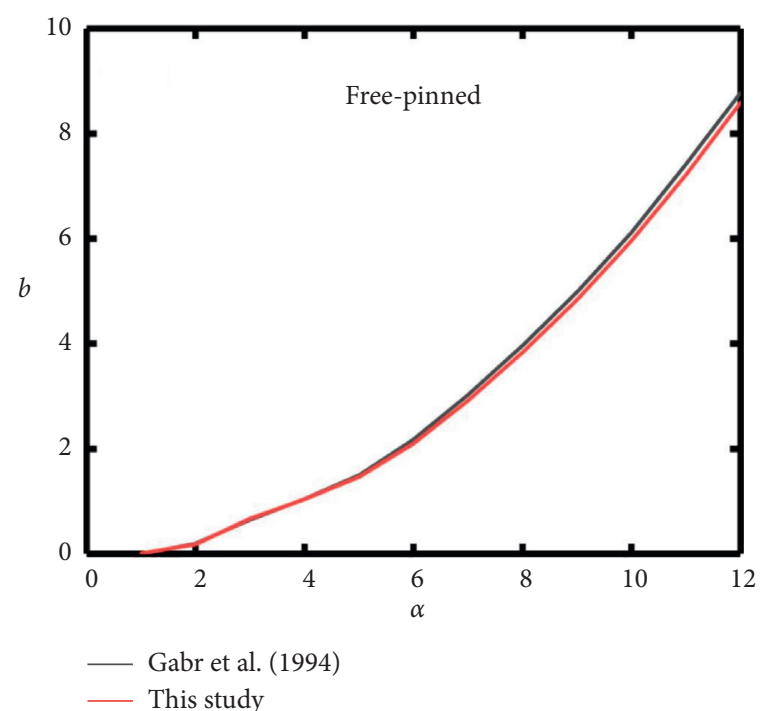

(b)

(a)

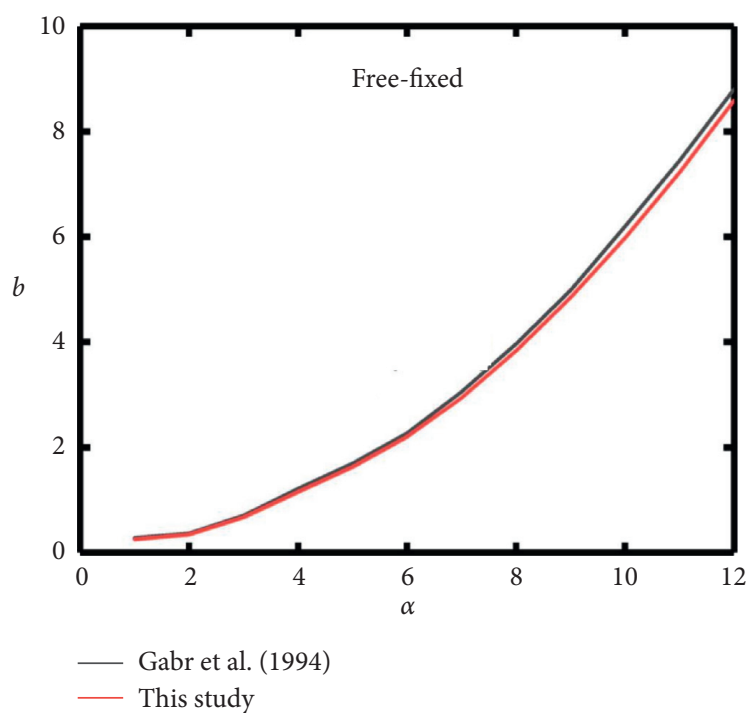

(c)

Figure 2: The buckling load factors of the uniform friction piles obtained by using the model of Gabr [14] and this study, for three different boundary conditions: free-free, free-pinned, and free-fixed.

show that the solution agrees well with Gabr's solution, which validates that the proposed model and solution method are suitable for investigating the buckling behaviors of the friction piles in soft soils.

3.2. Buckling Behaviors. In this section, the buckling load and buckling shape in the pile-soil system under various geometric and material conditions will be explored. In parametric study, typical geometric and material values commonly used in engineering are chosen. In the calculation, the parameters are set as $w_{e}=1 \mathrm{~m}, \lambda=2.5 \mathrm{~m}, E=10 \mathrm{GPa}, k_{\mathrm{e}}=10 \mathrm{MN} / \mathrm{m}^{3}$, and $f_{e}=100 \mathrm{kPa}$ [12]. Therefore, the approximate range of related dimensionless quantities are estimated as follows: $m=0-1, n=0-5, s=0-5, \alpha=0-10$, and $\beta=0-0.05$. It is noted that $\kappa$ depends on $\alpha$.
Figure 3 illustrates the dependence of buckling load on the friction ratio $s$ of the pile under different end restraints. It is noted that $s<1$ represents the softening of foundation with depth, and $s>1$ represents the hardening of foundation with depth. The results show that the buckling load $b$ decreases with increasing friction ratios regardless of end restraint, and the dependence of the buckling load on the friction ratio is most significant when $s$ is small. The results also show that the end conditions have a great influence on the buckling behaviors of the pile. For the stronger constrained pile, the buckling load is larger.

Figure 4 illustrates the influence of tapered ratio $m$ on dimensionless buckling load $b$ under several friction ratios $s$. The results show that no matter what the friction ratio is, the value of the dimensionless buckling load increases significantly at first and then decreases with the increase of the friction ratio. 


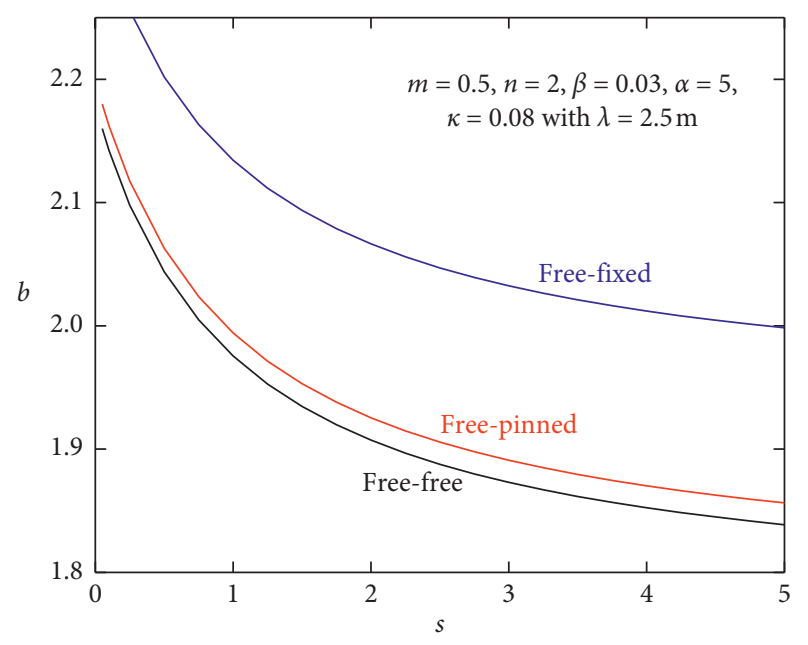

FIGURe 3: Dependence of the dimensionless buckling load $b$ on the friction ratio $s$ of the linear shaft friction, for three different boundary conditions: free-free, free-pinned, and free-fixed.

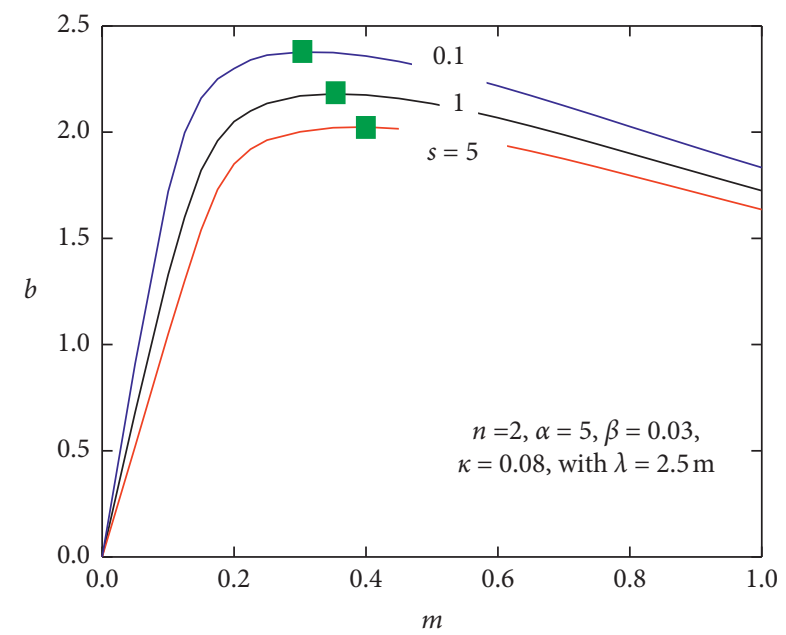

Figure 4: Dependence of the dimensionless buckling load $b$ on the tapered ratio $m$, for different friction ratios $s$.

This means that there exists an optimal tapered ratio $m_{\text {opt }}$ when other variables remain unchanged. When the tapered ratio is the optimal value, the buckling load of the pile reaches the maximum. Therefore, when other variables remain unchanged, this model can be used to obtain an optimal tapered ratio, which can maximize the flexural and buckling bearing capacity of piles. The optimal tapered ratio depicted by the green point decreases with the increase of the friction ratio.

The dependence of buckling load $s$ on the stiffness ratio of the frictional pile is shown in Figure 5. It is noted that $n>1$ corresponds to soil softening with depth and $n<1$ corresponds to soil hardening with depth. Similar to the effect of friction ratio, the dependence of the dimensionless buckling load on stiffness ratio $n$ is dominant in the cases with a relatively small $n$. The study also shows that the dimensionless buckling load $b$ increases significantly with the decrease of friction ratio $s$ regardless of stiffness.

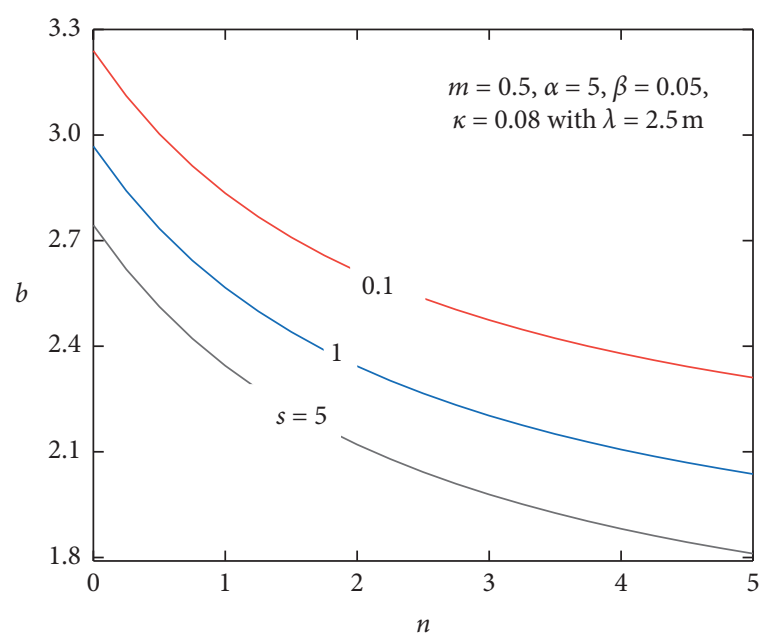

Figure 5: Dependence of the dimensionless buckling load $b$ on the stiffness ratio $n$ of the linear lateral stiffness, for different friction ratios $s$.

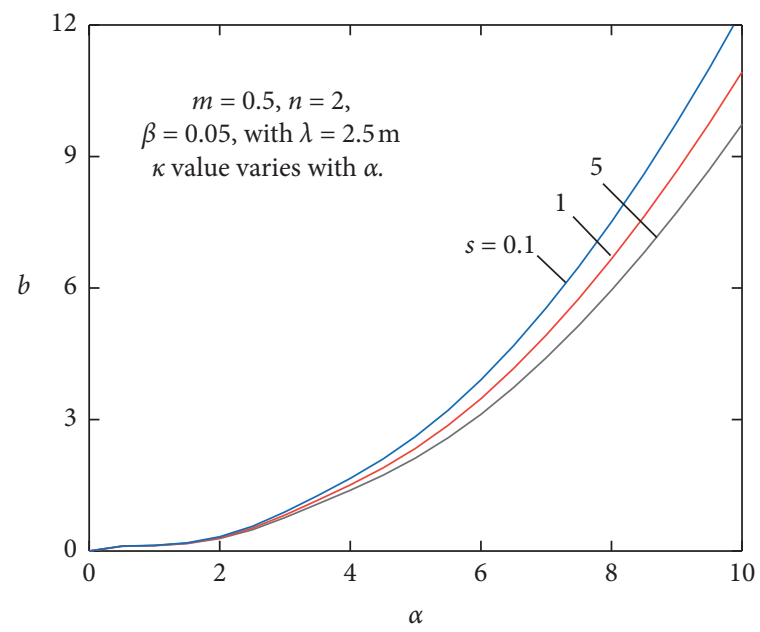

FIgURE 6: Dependence of the dimensionless buckling load $b$ on the dimensionless characteristic length $\alpha$, for different friction ratios $s$.

The influence of dimensionless characteristic length $\alpha$ on dimensionless buckling load of tapered friction pile is shown in Figure 6. With the increase of characteristic length $\alpha$, the value of dimensionless buckling load shows an increasing trend as a whole, and this general trend is observed under different friction ratios. When the characteristic length $\alpha$ is small, the results show that the influence can be neglected, indicating that the pile body is rigid. When the characteristic length $\alpha$ is large, this effect is very important, which means that the flexural stiffness of piles is lower than that of soil cushion. Some groups reported similar buckling behavior [35].

Figure 7 presents the influence of axial friction ratio on the dimensionless buckling load of tapered friction piles. Since the typical values of surface friction between soil and pile in engineering are between $0 \mathrm{kPa}$ and $100 \mathrm{kPa}, \beta$ can be estimated to be approximately $0 \sim 0.05$ [12]. The results show that the relationship between dimensionless buckling 


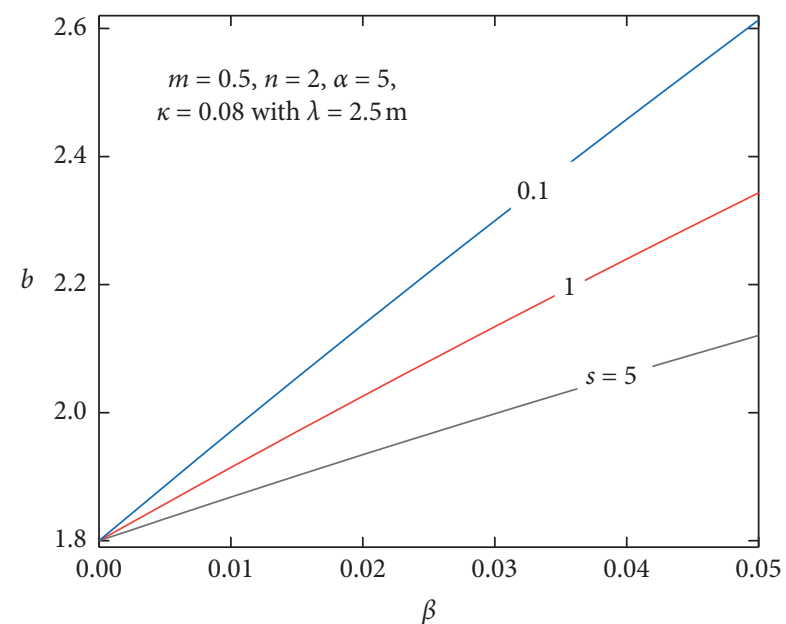

Figure 7: Dependence of the dimensionless buckling load $b$ on the friction $\beta$, for different friction ratios $s$.

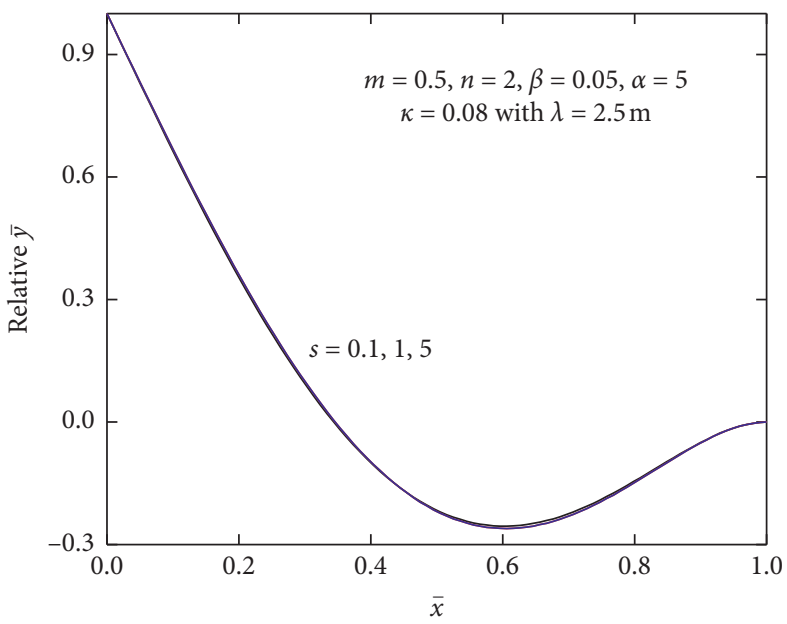

FIGURE 8: First buckling mode, for different friction ratios $s$.

load $b$ and friction is nearly linear. When $\beta=0$, which means that the axial load of the pile remains unchanged along the pile body, the pile can be considered to be end-bearing. When $\beta$ increases, which means that the load transferred along the pile body increases, and then will lead to the increase of the buckling load. It is also shown that the friction ratio has large impact on the dimensionless buckling load, where the slope the dimensionless buckling load significantly increases with the increase of the friction ratio.

Figure 8 illustrates the first buckling shapes of the tapered friction pile for free-fixed boundary and three different friction ratios $s$. It is shown that the buckling shapes for different friction ratios are approximately the same, although their dimensionless buckling loads are really different. This result implies that the buckling shape may be insensitive to the friction ratio for the piles with the same end constrains.

Figure 9 illustrates the dimensionless buckling stress distribution on the cross-section of tapered friction piles along the direction of depth, for four different friction ratios.

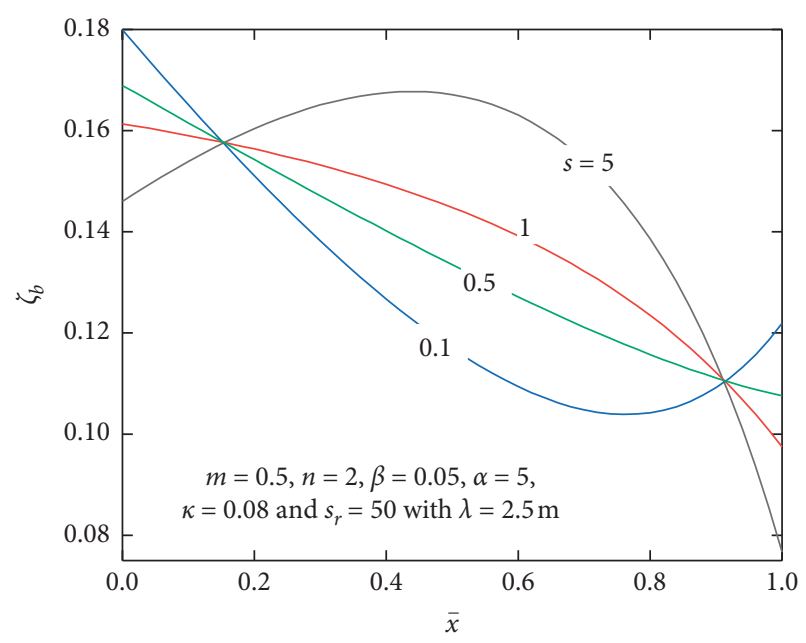

Figure 9: Stress field in the cross-section of piles, for different friction ratios $s$.

It is shown that the location of maximum buckling stress varies with the friction ratio. For $s=0.1,0.5$, and 1 , the maximum buckling stress occurs at the top of tapered piles, although there is the largest cross-sectional area. While for $s=5$, the maximum dimensionless buckling stress occurs at the cross-section in the middle section of tapered piles. According to the results of buckling stress, a criterion can be established to judge whether buckling is the main consideration in the pile design. Generally speaking, in pile engineering design, it is necessary to ensure that the buckling load is larger than the compressive load corresponding to the material yield stress in order to avoid buckling failure.

\section{Conclusion}

In this paper, the buckling behaviors of a pile in the heterogeneous soil with linear shaft friction and linear lateral stiffness are theoretically investigated. A theoretical model for investigating the stability of the tapered friction piles in soft soils is established and validated. The eigenvalue problem associated with fourth-order differential equilibrium equation and three different boundary conditions is formulated, and the solution module bvp4c in software Matlab is utilized to numerically solve the boundary value problem and obtain the critical buckling load and buckling shape. By comparing with the classic Gabr's solution, the model proposed in this paper is proved to be applicable to predicting the buckling behaviors of tapered friction piles.

Based on the proposed model and solution method, the effects of boundary conditions, tapered ratio, stiffness ratio, friction ratio, lateral stiffness, and shaft friction on the buckling behaviors of the friction piles with linear shaft friction are extensively explored. The results show that the friction ratio greatly affects the buckling load, and the buckling load increases with the decrease of the friction ratio. Furthermore, there exists an optimal tapered ratio corresponding to maximum dimensionless buckling load in the tapered friction pile with linear shaft friction, which is crucial in geoengineering design. This study demonstrates 
that the linear shaft friction should be considered in designing the tapered friction piles in inhomogeneous soils. The results also have potential applications in the fields of growing of tree roots in soils, moving of slender rods in viscous fluids, penetrating of fine rods in soft elastomers, etc.

\section{Data Availability}

No data were used to support this study as it mainly involves theoretical derivation and calculation.

\section{Conflicts of Interest}

The authors declare no conflicts of interest.

\section{Acknowledgments}

This study was supported by the National Natural Science Foundation of China (no. 51608005) and State Grid Anhui Electric Power Co., Ltd. Construction Company (no. SGAHJYJSXLJS1800417).

\section{References}

[1] N. Wang, K. Naruse, D. Stamenovic et al., "Mechanical behavior in living cells consistent with the tensegrity model," Proceedings of the National Academy of Sciences, vol. 98, no. 14, pp. 7765-7770, 2001.

[2] Y. Chen, X. Liao, Y. Liu, and X. Chen, "Helical buckling of wires embedded in a soft matrix under axial compression," Extreme Mechanics Letters, vol. 17, pp. 71-76, 2017.

[3] S. G. O'Keeffe, D. E. Moulton, S. L. Waters, and A. Goriely, "Growth-induced axial buckling of a slender elastic filament embedded in an isotropic elastic matrix," International Journal of Non-linear Mechanics, vol. 56, pp. 94-104, 2013.

[4] Y. Zhao, J. Li, Y. P. Cao, and X. Q. Feng, "Buckling of an elastic fiber with finite length in a soft matrix," Soft Matter, vol. 12, no. 7, pp. 2086-2094, 2016.

[5] T. Li, "A mechanics model of microtubule buckling in living cells," Journal of Biomechanics, vol. 41, no. 8, pp. 1722-1729, 2008.

[6] Y. Li, N. Kaynia, S. Rudykh, and M. C. Boyce, "Wrinkling of interfacial layers in stratified composites," Advanced Engineering Materials, vol. 15, no. 10, pp. 921-926, 2013.

[7] T. C. Maltby and C. R. Calladine, "An investigation into upheaval buckling of buried pipelines-I. experimental apparatus and some observations," International Journal of Mechanical Sciences, vol. 37, no. 9, pp. 943-963, 1995.

[8] J. L. Silverberg, R. D. Noar, M. S. Packer et al., "3D imaging and mechanical modeling of helical buckling in medicago truncatula plant roots," Proceedings of the National Academy of Sciences, vol. 109, no. 42, pp. 16794-16799, 2013.

[9] W. S. Klug, M. T. Feldmann, and M. Ortiz, "Three-dimensional director-field predictions of viral DNA packing arrangements," Computational Mechanics, vol. 35, no. 2, pp. 146-152, 2005.

[10] F. Xu, W. Lu, and Y. Zhu, "Controlled 3D buckling of silicon nanowires for stretchable electronics," ACS Nano, vol. 5, no. 1, pp. 672-678, 2011.

[11] T. Su, N. Wicks, J. Pabon, and K. Bertoldi, "Mechanism by which a frictionally confined rod loses stability under initial velocity and position perturbations," International Journal of Solids and Structures, vol. 50, no. 14-15, pp. 2468-2476, 2013.
[12] N. Vogt, S. Vogt, and C. Kellner, "Buckling of slender piles in soft soils," Bautechnik, vol. 86, no. S1, pp. 98-112, 2009.

[13] F. Liang, H. Zhang, and M. Huang, "Extreme scour effects on the buckling of bridge piles considering the stress history of soft clay," Natural Hazards, vol. 77, no. 2, pp. 1143-1159, 2015.

[14] D. R. Shields, "Buckling of micropiles," Journal of Geotechnical and Geoenvironmental Engineering, vol. 133, no. 3, pp. 334-337, 2007.

[15] H. Seo and M. Prezzi, "Analytical solutions for a vertically loaded pile in multilayered soil," Geomechanics and Geoengineering, vol. 2, no. 1, pp. 51-60, 2007.

[16] A. F. Ramirez-Henao and J. Paul Smith-Pardo, "Elastic stability of pile-supported wharves and piers," Engineering Structures, vol. 97, pp. 140-151, 2015.

[17] S. Prakash and H. D. Sharma, Pile Foundation in Engineering Practice, John Wiley \& Sons, Hoboken, NJ, USA, 1990.

[18] J. K. Lee and S. Jeong, "Flexural and torsional free vibrations of horizontally curved beams on Pasternak foundations," Applied Mathematical Modelling, vol. 40, no. 3, pp. 22422256, 2016.

[19] T. Su, J. Liu, D. Terwagne, P. M. Reis, and K. Bertoldi, "Buckling of an elastic rod embedded on an elastomeric matrix: planar vs. non-planar configurations," Soft Matter, vol. 10, no. 33, pp. 6294-6302, 2014.

[20] M. Nadeem, T. Chakraborty, and V. Matsagar, "Nonlinear buckling analysis of slender piles with geometric imperfections," Journal of Geotechnical and Geoenvironmental Engineering, vol. 141, no. 1, Article ID 06014014, 2015.

[21] M. Jesmani, S. H. Nabavi, and M. Kamalzare, "Numerical analysis of buckling behavior of concrete piles under axial load embedded in sand," Arabian Journal for Science and Engineering, vol. 39, no. 4, pp. 2683-2693, 2014.

[22] L. Muravyeva and N. Vatin, "Elaboration of the method for safety assessment of subsea pipeline with longitudinal buckling," Advances in Civil Engineering, vol. 2016, Article ID 7581360, 2016.

[23] A. A. Ghadban, A. H. Al-Rahmani, H. A. Rasheed, and M. T. Albahttiti, "Buckling of nonprismatic column on varying elastic foundation with arbitrary boundary conditions," Mathematical Problems in Engineering, vol. 2017, Article ID 5976098, 2017.

[24] M. Hetenyi, Beams on Elastic Foundation, University of Michigan Press, Ann Arbor, MI, USA, 1946.

[25] M. T. Davisson, "Estimating buckling loads for piles," in Proceedings of the 2nd Pan American conference on soil mechanics and foundation engineering, vol. 2, pp. 351-369, Mexico city, Mexico, November 1963.

[26] M. T. Davisson and K. E. Robinson, "Bending and Buckling of Partially Embedded Piles," in Proceeding of 6th International Conference on Soil Mechanics and Foundation Engineering, pp. 243-246, Montreal, Canada, September 1965.

[27] A. S. Reddy and A. J. Valsangkar, "Buckling of fully and partially embedded piles," Journal of Soil Mechanics \& Foundations Division, vol. 96, no. 6, 1970.

[28] R. P. West, M. E. Heelis, M. N. Pavlović, and G. B. Wylie, "Stability of end-bearing piles in a non-homogeneous elastic foundation," International Journal for Numerical and Analytical Methods in Geomechanics, vol. 21, no. 12, pp. 845-861, 1997.

[29] Y. H. Chen, L. Chen, X. Q. Wang, and G. Chen, "Critical buckling load calculation of piles based on cusp catastrophe theory," Marine Georesources \& Geotechnology, vol. 33, no. 3, pp. 222-228, 2015. 
[30] T. Deng, Q. Liu, and M. Huang, "Buckling of fully embedded single piles by using the modified Vlasov foundation model," International Journal of Structural Stability and Dynamics, vol. 17, no. 01, Article ID 1750007, 2017.

[31] M. A. Gabr, J. J. Wang, and M. Zhao, "Buckling of piles with general power distribution of lateral subgrade reaction," Journal of Geotechnical and Geoenvironmental Engineering, vol. 123, no. 2, pp. 123-130, 1997.

[32] S. R. Dash, S. Bhattacharya, and A. Blakeborough, "Bendingbuckling interaction as a failure mechanism of piles in liquefiable soils," Soil Dynamics and Earthquake Engineering, vol. 30, no. 1-2, pp. 32-39, 2010.

[33] M. E. Heelis, M. N. Pavlović, and R. P. West, "The analytical prediction of the buckling loads of fully and partially embedded piles," Géotechnique, vol. 54, no. 6, pp. 363-373, 2004.

[34] M. A. Gabr, J. Wang, and S. A. Kiger, "Effect of boundary conditions on buckling of friction piles," Journal of Engineering Mechanics, vol. 120, no. 6, pp. 1392-1400, 1994.

[35] J. K. Lee, S. Jeong, and Y. Kim, "Buckling of tapered friction piles in inhomogeneous soil," Computers and Geotechnics, vol. 97, pp. 1-6, 2018.

[36] J. K. Lee, "A unified model for analyzing free vibration and buckling of end-bearing piles," Ocean Engineering, vol. 152, pp. 17-25, 2018.

[37] J. K. Lee, S. H. Park, and Y. Kim, "Transverse free vibration of axially loaded tapered friction piles in heterogeneous soil," Soil Dynamics and Earthquake Engineering, vol. 117, pp. 116-121, 2019.

[38] Y. Liu, L. Q. He, Y. J. Jiang, M. M. Sun, E. J. Chen, and F. H. Lee, "Effect of in situ water content variation on the spatial variation of strength of deep cement-mixed clay," Géotechnique, vol. 69, no. 5, pp. 391-405, 2019. 